\title{
Association between Toxoplasma Infection and Bad Obstetric Outcomes in Women from Kirkuk
}

\author{
Alsamarai AM1,2*, Hassan $\mathrm{HMM}^{3}{ }^{3}$, Alobaidi AHA ${ }^{4}$, Ghali- AL-Salihi F ${ }^{5}$ and \\ Aljumaily ZK6 \\ 1Departments of Medicine and Microbiology, Tikrit University College of Medicine, Tikrit, \\ Iraq \\ ${ }^{2}$ Aalborg Academy of Science, Denmark \\ ${ }^{3}$ Department of Microbiology, Tikrit University College of Veterinary Medicine, Iraq \\ ${ }^{4}$ Department of Biochemistry, Tikrit University College of Science Tikrit, Iraq \\ ${ }^{5}$ Department of Basic Sciences, Kirkuk University College of Veterinary Medicine, Kirkuk, Iraq \\ ${ }^{6}$ Kirkuk Health Authority
}

*Corresponding author: Prof. Abdulghani Alsamarai, Departments of Medicine and Microbiology, Tikrit University College of Medicine, Tikrit, Iraq, Tel: 009647701831295; Email: galsamarrai@yahoo.com; galsamarrai@hotmail.com

\section{Abstract}

Toxoplasmosis gondii infection is one of the predominant chronic infections with global distribution and characterized by regional geographical variations. The disease was with social, economic and health impact because its association with bad obstetric outcomes. To determine the association between Toxoplasma infections and bad obstetric outcomes this study was conducted as a descriptive case control study. The study included 547 women with BOH and 291 women with normal pregnancy outcome. Serological study carried out to determine T. gondii IgG and IgM using ELISA kits. T. gondii IgG overall prevalence was $24.7 \%$. The seroprevalence was not significantly different in BOH women as compared to control, but seroprevalence was significantly lower in pregnant women (18.3\%) than in non pregnant (31.5\%) women. The current T. gondii infection overall rate was $0.84 \%$, with significantly higher rate in women with $\mathrm{BOH}(1.3 \%)$. Residence influenced T. gondii IgG and IgM seroprevalence. In conclusion, Toxoplasma seropositivity was not significantly different in women with $\mathrm{BOH}$ as compared to control and significantly influenced by residence.

Keywords: Torch; BOH; Toxoplasma; Pregnancy; Iraq 


\section{Introduction}

Toxoplasmosis gondii infection is one of the predominant chronic infections with global distribution and characterized by regional geographical variations [1]. The disease was with social, economic and health impact because its association with bad obstetric outcomes [2]. The parasite induced lifelong immunity following primary infection, however, it remains as latent infection within the host. Possible reactivation of latent infection in an increasingly immunosuppressed population, however, makes toxoplasmosis an important opportunistic infection. T. gondii infection in pregnant women may lead to vertical transmission from mother to the fetus and subsequent intrauterine deformity [3].

Alsamarai in a recent review summarized 65 studies that reported $\mathrm{T}$. gondii prevalence in women from different countries and fifty nine studies from Arab countries, of them 30 studies were from Iraq. Community based studies form $3.3 \%$ and the most of the studies were a hospital based studies and sample size with a wide range [2]. Antibodies to T. gondii were detected in most of the studies by Enzyme Linked Immunosorbent Assay. T. gondii remote infections as determined by IgG prevalence estimation was with a range of $5.3 \%$ in Thailand to $75 \%$ in Brazil, while IgM range was $0 \%$ in Vietnam and China to $76.1 \%$ in Ghana [4-8]. While in female with adverse outcome IgG seroprevalence with range of $19.44 \%$ to $55.2 \%$ in Nepal and acute infections (IgM) with range of $6.97 \%$ to $42.5 \%$ in India [9-12]

In studies performed in Arab countries, the IgG seroprevalence range was $15.8 \%$ in Bahrain to $94 \%$ in Iraq, while acute infection (IgM) was reported with a range of 2.8\% in Egypt to 55.5\% in Iraq [13-16]. However, in women with bad obstetric outcome IgG seroprevalence range was $6.84-77.1 \%$, while IgM seroprevalence range was $0.97 \%$ - $58 \%$ [17-20]. In respect to the above information a gap was present in the epidemiological data

\section{Virology \& Immunology Journal}

of toxoplasmosis, its risk and determinant in women with bad obstetric outcomes. The aim of the present study is to provide a picture about frequency, distribution, risk and determinants of the seroprevalence of T. gondii infections during pregnancy and their association with high delivery risk factors.

\section{Patients and Methods}

\section{Patients}

Descriptive case control study was performed in Kirkuk General Hospital and the details of the study design and study population was described previously [21].

\section{T. gondii IgM and IgG antibodies determination}

IgM and IgG for T. gondii were detected using Enzyme Linked Immunosorbent Assay kit that was purchased from BioCheck, Inc, 323 Vintage Park Dr, Foster City, CA 94404.

\section{Statistical Analysis}

Data analyzed using SPSS [Version 16] to determine Chi and odd ratio.

\section{Results}

T. gondii IgG overall seroprevalence was $24.7 \%$, with no significant difference $\left(\mathrm{X}^{2}=2.35, \mathrm{P}>0.05\right)$ between women with $\mathrm{BOH}(23 \%)$ and women with normal pregnancy (27.8\%). Table 2 However, the was significant difference $\left(\mathrm{X}^{2}=17.72, \quad \mathrm{P}=0.000\right)$ between pregnant $(18.3 \%)$ and non pregnant (31.5\%) women. Table 3 The current T. gondii infection overall rate was $0.84 \%$, with significant $\left(\mathrm{X}^{2}=3.76, \mathrm{P}=0.05\right)$ lower rate in women with normal pregnancy as compared to those with $\mathrm{BOH}$ $(1.3 \%)$.

\begin{tabular}{|c|c|c|c|}
\hline \multicolumn{1}{|c|}{ Group } & Number & Mean age \pm SD in years \\
\hline \multirow{2}{*}{$\begin{array}{c}\text { Women with bad obstetric } \\
\text { history }\end{array}$} & Pregnant & 292 & $28.35 \pm 7.25$ \\
\cline { 2 - 4 } & Non pregnant & 255 & $28.24 \pm 6.81$ \\
\cline { 2 - 4 } & Total & 547 & $27.40 \pm 6.24$ \\
\hline \multirow{2}{*}{$\begin{array}{c}\text { Women with normal } \\
\text { pregnancy }\end{array}$} & Pregnant & 140 & $28.06 \pm 10.51$ \\
\cline { 2 - 4 } & Non pregnant & 151 & $28.42 \pm 7.72$ \\
\hline \multicolumn{2}{|c|}{ Grand total } & 291 & \\
\hline P value & ANOVA NS \\
\hline
\end{tabular}

Table 1: Study population. 


\section{Virology \& Immunology Journal}

\begin{tabular}{|c|c|c|c|}
\hline \multicolumn{2}{|c|}{ Group [Number] } & \multicolumn{2}{c|}{ Number positive [Percent] } \\
\cline { 2 - 4 } & IgG \\
\hline \multirow{4}{*}{ Bad obstetric history } & Pregnant [292] & $4[1.4]$ & $66[22.6]$ \\
\cline { 2 - 4 } & Non- pregnant [255] & $3[1.2]$ & $60[23.5]$ \\
\cline { 2 - 4 } & $\mathrm{X}^{2}$ & 0.04 & 0.066 \\
\cline { 2 - 4 } & P value & NS & NS \\
\cline { 2 - 4 } & Total [547] & $\mathbf{7}[\mathbf{1 . 3}]$ & $\mathbf{1 2 6}[\mathbf{2 3}]$ \\
\hline \multirow{4}{*}{ Normal pregnancy } & Pregnant [140] & $0[0]$ & $13[9.3]$ \\
\cline { 2 - 4 } & Non- pregnant [151] & $0[0]$ & $68[45]$ \\
\cline { 2 - 4 } & $\mathrm{X}^{2}$ & - & $\mathbf{0}$ \\
\cline { 2 - 4 } & P value & - & $\mathbf{8 1}[\mathbf{2 7 . 8}]$ \\
\cline { 2 - 4 } & Total [291] & $\mathbf{0}[\mathbf{0}]$ & $207[24.7]$ \\
\hline Grand total [838] & $7[0.84]$ & 2.35 \\
\hline \multicolumn{2}{|c|}{$\mathrm{X}^{2}$ BOH versus Normal Pregnancy } & 3.76 & NS \\
\hline \multicolumn{2}{|c|}{ P value BOH versus Normal Pregnancy } & $\mathbf{0 . 0 5}$ & \\
\hline
\end{tabular}

Table 2: Toxoplasma seroprevalence in women with bad obstetric history.

\begin{tabular}{|c|c|c|}
\hline \multirow{2}{*}{ Group [Number] } & \multicolumn{2}{|c|}{ Number positive [Percent] } \\
\cline { 2 - 3 } & IgM & IgG \\
\hline Pregnant [432] & $4[0.9]$ & $79[18.3]$ \\
\hline Non- pregnant [406] & $3[0.7]$ & $128[31.5]$ \\
\hline $\mathrm{X}^{2}$ & 0.088 & 19.72 \\
\hline P value & NS & $\mathbf{0}$ \\
\hline
\end{tabular}

Table 3: Toxoplasma seroprevalence in pregnant compared to non-pregnant women.

T. gondii IgG and IgM were not significantly varied with age. The majority $(71.4 \%, 5 / 7)$ of current infection cases was in women win age of 20 -39 years, and IgM not detected in the age groups of 14-19 and 40-48 years for both patients and control groups. $T$. gondii $\operatorname{IgG}$ seroprevalence was $26.7 \%$ in $\mathrm{BOH}$ women with age of $<20$ years, while the corresponding value in control was $34.04 \%$, but the difference was not significant. Then decline to reach about the same values for the other 3 age groups. However, in control the prevalence rate was $34.04 \%$ in women at age $14-19 \mathrm{yrs}$, then decline to reach $2.38 \%$ in women with $20-29$ yrs age. In addition, it increases in older ages to reach $100 \%$ seropositivity rate in those with age of 40-48yes. Thus there was a significant differences in seroprevalence $\left(\mathrm{X}^{2}=127, \mathrm{P}=0.000\right)$, between age groups, Table 4 .

\begin{tabular}{|c|c|c|c|c|c|c|c|c|c|c|}
\hline \multirow{2}{*}{ Age group in years } & \multicolumn{5}{|c|}{ IgM Number positive $\backslash$ total [\%] } & \multicolumn{5}{|c|}{ IgG Number positive $\backslash$ total [\%] } \\
\hline & Control & Patient & $\mathbf{X}^{2}$ & P value & Total & Control & Patient & $\mathbf{X}^{2}$ & $P$ value & Total \\
\hline $14-19$ & $0 \backslash 47[0]$ & $0 \backslash 45[0]$ & ND & - & $\begin{array}{c}0 / 92 \\
{[0]}\end{array}$ & $\begin{array}{c}16 \backslash 47 \\
{[34.04]}\end{array}$ & $\begin{array}{l}12 \backslash 45 \\
{[26.7]} \\
\end{array}$ & 0.59 & NS & $\begin{array}{l}28 / 92 \\
{[30.4]} \\
\end{array}$ \\
\hline $20-29$ & $\begin{array}{c}0 \backslash 126 \\
{[0]}\end{array}$ & $\begin{array}{c}\backslash 240 \\
{[2.1]} \\
\end{array}$ & 2.7 & NS & $\begin{array}{c}5 / 366 \\
{[1.4]}\end{array}$ & $\begin{array}{l}3 \backslash 126 \\
{[2.38]}\end{array}$ & $\begin{array}{c}49 \backslash 240 \\
{[20.4]}\end{array}$ & 22 & $\mathbf{0}$ & $\begin{array}{c}52 / 366 \\
{[14.2]}\end{array}$ \\
\hline $30-39$ & $\begin{array}{c}0 \backslash 86 \\
{[0]}\end{array}$ & $\begin{array}{l}2 \backslash 214 \\
{[0.83]}\end{array}$ & 0.8 & NS & $\begin{array}{c}2 / 300 \\
{[0.7]} \\
\end{array}$ & $\begin{array}{l}30 \backslash 86 \\
{[34.9]}\end{array}$ & $\begin{array}{l}45 \backslash 214 \\
{[21.03]} \\
\end{array}$ & 6.28 & 0.01 & $\begin{array}{c}75 / 300 \\
{[25]}\end{array}$ \\
\hline $40-48$ & $\begin{array}{c}0 \backslash 32 \\
{[0]}\end{array}$ & $\begin{array}{c}0 \backslash 48 \\
{[0]}\end{array}$ & ND & - & $\begin{array}{c}0 / 80 \\
{[0]}\end{array}$ & $\begin{array}{l}32 \backslash 32 \\
{[100]}\end{array}$ & $\begin{array}{l}10 \backslash 48 \\
{[20.8]}\end{array}$ & 48.3 & $\mathbf{0}$ & $\begin{array}{l}42 / 80 \\
{[52.5]}\end{array}$ \\
\hline $\mathrm{X}^{2}$ & ND & 2.63 & & & 2.8 & 127 & 0.9 & & & 60 \\
\hline P value & - & NS & & & NS & 0 & NS & & & $\mathbf{0}$ \\
\hline
\end{tabular}

Table 4: Comparison of Frequency of Toxoplasma in BOH compared to control agents in regard to age. 


\section{Virology \& Immunology Journal}

Data pooling shows that acute infection was higher $(1.4 \%)$ in the women with age of $20-29$ years as compared to other age groups $\left(\mathrm{X}^{2}=2.8, \mathrm{P}>0.05\right)$. T. gondii IgG seropositivity was lower (14.2\%) in women with age of 20-29 yrs, while the highest prevalence $(52.5 \%)$ in women with age of 40-48 years $\left(\mathrm{X}^{2}=60, \mathrm{P}=0.000\right)$. Furthermore, IgG seroprevalence was 5 times $\left(\mathrm{X}^{2}=60.32\right.$, $\mathrm{P}=0.0001$ ) in women with age of $\geq 30 \quad(10.9 \%)$ as compared to those $<30$ yrs $(52.5 \%)$ in control group. However, in patient group, the IgG seroprevalence was about the same in women above and below 30 yrs of age. Although, when the whole data pooled there was significantly $\left(\mathrm{X}^{2}=20.6, \mathrm{P}=0.000\right)$ higher $(30.8 \%)$ in women with age of $\geq 30$ yrs than those of $<3$ o yrs $(17.5 \%)$, Table 5.

\begin{tabular}{|c|c|c|c|c|c|c|c|c|c|}
\hline \multirow{2}{*}{ Igs } & \multirow{2}{*}{ Age in years. } & \multicolumn{3}{|c|}{ Number. } & \multicolumn{5}{|c|}{ Number positive [\%] } \\
\hline & & Control & Patient & Total & Control & Patient & $\mathrm{X}^{2}$ & $\mathbf{P}$ & Total \\
\hline \multirow{4}{*}{ IgM } & $14-29$ & 173 & 285 & 458 & $0[0]$ & $\begin{array}{c}5 \\
{[1.8]}\end{array}$ & 1.66 & NS & 5 [1.1] \\
\hline & $30-48$ & 118 & 262 & 380 & $0[0]$ & $\begin{array}{c}2 \\
{[0.8]}\end{array}$ & 0.91 & NS & $2[0.53]$ \\
\hline & $\mathrm{X}^{2}$ & & & & ND & 1.06 & & & 0.8 \\
\hline & $\mathrm{P}$ & & & & - & NS & & & NS \\
\hline \multirow{4}{*}{$\operatorname{IgG}$} & $14-29$ & 173 & 285 & 458 & 19 [10.9] & $61[21.4]$ & 8.11 & 0.004 & 80 [17.5] \\
\hline & $30-48$ & 118 & 262 & 380 & $62[52.5]$ & $55[21]$ & 38 & 0 & $117[30.8]$ \\
\hline & $\mathrm{X}^{2}$ & & & & 60.32 & 0.01 & & & 20.5 \\
\hline & $\mathrm{P}$ & & & & 0.0001 & NS & & & 0 \\
\hline
\end{tabular}

Table 5: Frequency of Toxoplasma according to age of $<30$ and above.

There was a significantly $\left(\mathrm{X}^{2}=8.11, \mathrm{P}=0.004\right)$ higher IgG seroprevalence $(21.4 \%)$ in women with $\mathrm{BOH}$ as compared to control $(10.9 \%)$ with age of $<30 \mathrm{yrs}$. However, in women with age of $\geq 30$ yrs there was significant lower $\left(\mathrm{X}^{2}=38, \mathrm{P}=0.000\right)$ in $\mathrm{BOH}(21 \%)$ as compared to control (52.5\%), Table 5. OR confirmed the association between $\mathrm{T}$. gondii IgG seroprevalence $(\mathrm{OR}=8.97, \mathrm{P}=0.000)$ and age of $<$ or $>30 \mathrm{yrs}$, but not IgM, Table 6.

\begin{tabular}{|c|c|c|}
\hline Variable & Odd ratio [95\% Confidence interval] & P value \\
\hline Toxoplasma IgM & $2.320[0.44-12.069]$ & NS \\
\hline Toxoplasma IgG & $8.974[4.934-16.319]$ & $\mathbf{0}$ \\
\hline
\end{tabular}

Table 6: Odd ratio of Toxoplasma in regards to age of women lower than 30 years.

T. gondii IgG seroprevalence was significantly higher $(\mathrm{X} 2=6.94, \mathrm{P}=0.005)$ in women living urban areas $(26.3 \%)$ as compared to women lining in rural (16.1\%) areas. However, current infection was significantly $\left(X^{2}=5.13\right.$,
$\mathrm{P}=0.036)$ predominant in rural areas $(2.9 \%)$ than in urban $(0.5 \%)$ areas, Table 7. Both T. gondii IgM $(\mathrm{OR}=5.48$, $\mathrm{P}=0.04)$ and $\operatorname{IgG}(\mathrm{OR}=1.85, \mathrm{P}=0.009)$, show significant association with residence, Table 8. 


\section{Virology \& Immunology Journal}

\begin{tabular}{|c|c|c|c|}
\hline \multirow{2}{*}{ Variable } & \multirow{2}{*}{ [Number] } & \multicolumn{2}{|c|}{ Number positive [Percent] } \\
\hline & & IgM & IgG \\
\hline \multirow{4}{*}{ Residence } & Rural [174] & $5[2.9]$ & 28 [16.1] \\
\hline & Urban [373] & $2[0.55]$ & 98 [26.3] \\
\hline & $\mathrm{X}^{2}$ & 5.131 & 6.938 \\
\hline & P value & 0.036 & 0.005 \\
\hline \multirow{4}{*}{ Occupation } & House wife [502] & $7[1.4]$ & 114 [22.7] \\
\hline & Working [45] & $0[0]$ & 13 [28.9] \\
\hline & $\mathrm{X}^{2}$ & 0.636 & 0.365 \\
\hline & $P$ value & NS & NS \\
\hline \multirow{4}{*}{ Education } & Uneducated [142] & $1[0.7]$ & $35[24.6$ \\
\hline & Educated [405] & $6[1.5]$ & 91 [22.5] \\
\hline & $\mathrm{X}^{2}$ & 0.5 & 0.28 \\
\hline & $P$ value & NS & NS \\
\hline \multirow{4}{*}{ Crowding Index } & $\leq 3[382]$ & 7 [10.8] & $96[25.1]$ \\
\hline & $3.1-8[165]$ & $0[0]$ & 30 [18.2] \\
\hline & $\mathrm{X}^{2}$ & 1.78 & 2.76 \\
\hline & P value & NS & NS \\
\hline \multirow{4}{*}{ Smoking } & Present [327] & $3[0.92]$ & $68[20.8]$ \\
\hline & No smoking [220] & 4 [1.8] & $58[26.4]$ \\
\hline & $\mathrm{X}^{2}$ & 0.845 & 2.3 \\
\hline & P value & NS & NS \\
\hline \multirow{4}{*}{ Hemoglobin } & $<11[151]$ & $2[1.3]$ & 32 [21.2] \\
\hline & $11-19[396]$ & 5 [1.3] & 94 [23.7] \\
\hline & $\mathrm{X}^{2}$ & 0.14 & 0.27 \\
\hline & P value & NS & NS \\
\hline \multirow{4}{*}{ Animal exposure } & Present [194] & $0[0]$ & $40[20.6]$ \\
\hline & Absent [353] & $7[1.1]$ & $86[24.4]$ \\
\hline & $\mathrm{X}^{2}$ & 3.89 & 0.99 \\
\hline & P value & 0.04 & NS \\
\hline \multirow{4}{*}{ Abortion number } & $1-2[116]$ & $4[3.4]$ & 32 [27.6] \\
\hline & $3-8[431]$ & $3[0.7]$ & 94 [21.8] \\
\hline & $\mathrm{X}^{2}$ & 5.34 & 1.41 \\
\hline & P value & 0.02 & NS \\
\hline \multirow{4}{*}{ Congenital anomalies } & Absent [498] & $7[1.4]$ & 118 [23.7] \\
\hline & Present [49] & $0[0]$ & 8 [16.3] \\
\hline & $\mathrm{X}^{2}$ & 0.698 & 1.366 \\
\hline & P value & NS & NS \\
\hline
\end{tabular}

Table 7: Frequency of Toxoplasma IgG and IgM in regard to sociodemographic characteristics. 


\section{Virology \& Immunology Journal}

\begin{tabular}{|c|c|c|c|}
\hline \multicolumn{2}{|l|}{ Variable } & \begin{tabular}{|c|} 
Odd ratio [95\% Confidence \\
interval]
\end{tabular} & $P$ value \\
\hline \multirow{2}{*}{ Occupation [Housewife versus Official] } & $\operatorname{IgM}$ & $1.377[0.077-24.538]$ & NS \\
\hline & $\operatorname{IgG}$ & $0.723[0.367-1.424]$ & NS \\
\hline \multirow{2}{*}{$\begin{array}{l}\text { Crowding Index } \\
{[<3 \text { versus }>3]}\end{array}$} & IgM & $0.151[0.009-2.664]$ & NS \\
\hline & $\operatorname{IgG}$ & $1.511[0.955-2.388]$ & NS \\
\hline \multirow{2}{*}{ Education [Educated versus Uneducated] } & IgM & $6.757[1.486-30.712]$ & 0.01 \\
\hline & IgG & $1.285[0.772-2.138]$ & NS \\
\hline \multirow{2}{*}{ [Rural versus Urban] } & IgM & $5.488[1.054-28.574]$ & 0.04 \\
\hline & IgG & $1.858[1.166-2.959]$ & 0.009 \\
\hline \multirow{2}{*}{ Smoking } & $\operatorname{IgM}$ & $2.000[0.443-9.025]$ & NS \\
\hline & IgG & $1.364[0.913-2.038]$ & NS \\
\hline \multirow{2}{*}{ Hemoglobin } & IgM & $0.953[0.183-4.964]$ & NS \\
\hline & IgG & $0.864[0.549-1.360]$ & NS \\
\hline \multirow{2}{*}{ Animal exposure } & IgM & $0.256[0.031-2.097]$ & NS \\
\hline & IgG & $0.806[0.527-1.233]$ & NS \\
\hline \multirow{2}{*}{ Abortion number } & IgM & $5.095[1.124-23.096]$ & 0.03 \\
\hline & IgG & $1.366[0.856-2.178]$ & NS \\
\hline \multirow{2}{*}{ Congenital anomalies } & IgM & $1.511[0.086-26.848]$ & NS \\
\hline & IgG & $1.591[0.726-3.490]$ & NS \\
\hline
\end{tabular}

Table 8: Association of Toxoplasma seropositivity with sociodemographic characteristics using Bivariate analysis.

T. gondii IgG seroprevalence was lower in housewife $(22.7 \%)$ as compared to working women $(28.9 \%)$, but the difference not reach significant level $\left(\mathrm{X}^{2}=0.36, \mathrm{P}>0.05\right)$. In addition, all the current $\mathrm{T}$. gondii infections were in housewife women. Furthermore, OR not confirm the association between occupation and both IgG and IgM seropositivity (Tables 7 \& 8).

T. gondii IgG seroprevalence was higher in uneducated women with $\mathrm{BOH}(24.6 \%)$ in comparison to educated women with BOH $(22.5 \%)$, however the difference was not statistically significant $\left(\mathrm{X}^{2}=0.28, \mathrm{P}>0.05\right)$. OR not confirm an association between Toxoplasma remote infections and education. Current infection was with twice time higher in educated (1.5\%) as compared to uneducated $(0.7 \%)$ women with $\mathrm{BOH}$, however, the difference was not significant $\left(\mathrm{X}^{2}=0.5, \mathrm{P}>0.05\right)$. However, OR confirmed T. gondii seropositivity and education for current infection $(\mathrm{IgM})(\mathrm{OR}=6.757, \mathrm{P}=0.01)$ (Tables $7 \&$ 8).

T. gondii IgG and IgM seroprevalence was lower in families with $\mathrm{CI}$ of $\geq 3$, however, OR not confirmed an association between $\mathrm{T}$. gondii infection and family size in women included in our study population (Tables $7 \& 8$ ).
Both T. gondii acute and remote infections not show a significant differences between smoker $(\operatorname{IgM}=0.92 \%$, $\operatorname{IgG}=20.84 \%)$ as compared to non- smoker (IgM=1.8\%, IgG $=26.4 \%$ ) women with BOH, (Table 7\& 8).

T. gondii IgG seroprevalence was about the same in $\mathrm{BOH}$ women with hemoglobin of $<11 \mathrm{~g} / \mathrm{dl}$ and with $>11$ $\mathrm{g} / \mathrm{dl}$, for both IgM and IgG. In addition, animal exposure was not significantly associated with both acute and remote Toxoplasma infections in women with bad obstetric outcomes (Tables 7 \& 8). Congenital anomalies were not significantly associated with acute and remote infections, however, this finding may be influenced by low number of those with history of congenital anomalies, (Tables $7 \&$ 8).

\section{Discussion}

The result of the present study indicated that that $24.7 \%$ of child bearing age women in Kirkuk , Iraq was seropositive for T. gondii. Thus $75.3 \%$ of studied population were susceptible to infection with T. gondii and was consistent to the recent findings reported for Kirkuk [1]. These two studies postulated that pregnant women in Kirkuk must take precaution to prevent their infections, which include proper meat cooking, sound 
meat handling and working in soil, and not to get in contact with cat feces [22].

The result of this study and that reported by others, indicated the endemicity of Toxoplasmosis in Kirkuk with a high rate of remote infection and low rate of acute infection [1,2]. Previously reported studies indicating variability in seroprevalence and transmission risk factors for $T$. gondii infections between geographical regions and countries [23]. In the present study T. gondii IgG/IgM antibodies predominance was 29 times. Thus $T$. gondii remote infection in our study cohort indicated that between $1 / 4$ to $1 / 3$ had experienced earlier infection, and these values are broadening in consistent with studies from Iraq and other countries $[1,23,24]$.

T. gondii IgG seropositivity across the age groups revealed a different pattern from that of IgM. In $85.8 \%$ of woman with age group of 20- 29 years were negative for T. gondii IgG and these 4/5 of them were susceptible for $T$. gondii infection during their pregnancy, indicating a high possibility of pregnancy adverse effect in Kirkuk population and confirm previous report for the same region [1].

However, the T. gondii IgG seropositivity was higher in 14-19 years (30.4\%) age group as compared to 20-29 years $(14.2 \%)$ age group. Then increased with age to reach the highest prevalence in age of $40-48$ (52.5\%) years of age. This could be attributed to less meat consumption and catabolism of passively transferred antibodies, then marked increase in seroprevalence was shown age class increase and this finding was consistent with previous reports in other geographical areas, peaking in the older subjects [2,25]. However, the susceptibility to infection was higher in the age of 2029years, reflecting a health problem in Kirkuk population. Thus age is a risk factor for Toxoplasma infection. However studies reported for Iraq indicated that T. gondii IgG seroprevalence reduced with age, with the exception of recently reported study for Kirkuk, which consistent with the present study finding [1,2]. This variation in association between age and infection may be attributed to variability of environmental fecal cat density $[23,25]$.

The T.gondii seroprevalence was significantly higher in women with $\geq 30$ years of age in control group, while there was no such difference in women with BOH. In younger women, $T$. gondii seroprevalence was significantly higher in women with $\mathrm{BOH}$ who were with age of $<30$ year, while it was higher in control as compared to women with $\mathrm{BOH}$ in the age of more than 30

\section{Virology \& Immunology Journal}

yrs. OR confirmed the association between T. gondii seroprevalence and age of $<30$ years.

Sub-grouping in to control and women with $\mathrm{BOH}$, shows that prevalence trend in patients was different from the pooled data and there was no significant differences among the age groups. However, the control group shows the same trend of pooled data. In addition, current T. gondii infection was not detected in control group, while it was detected in $1.7 \%$ of women with $\mathrm{BOH}$.

The overall T. gondii IgG seroprevalence $(27.8 \%)$ in woman from Kirkuk governorate was lower to reported studies from Egypt, Morocco, Saudi Arabia, Iraq, Libya, Tunisia, Lebanon, Sudan, and Jordan [2,26]. However, this study finding was similar to that reported for Egypt, and Saudi Arabia. Although the seropositivity of T. gondii IgG was higher in $7 / 30$ studies in Iraq, Bahrain and Palestine [2]. Arab countries studies seroprevalence shows geographical variations.

In, Kirkuk, 4 studies were reported, one study reported seroprevalence of $61 \%$ in pregnant woman and in $74.22 \% \mathrm{BOH}$ non pregnant, while other found that $36.6 \%$ of pregnant woman and $52 \%$ of aborted woman, giving overall seroprevalence of $44.3 \%$ [2]. In addition, a very low (4.84\%) seroprevalence of IgG in woman with adverse outcome reported by other. In a recently reported study, the seroprevalence was $27 \%$ in women with $\mathrm{BOH}$, and in $31.4 \%$ in control group, and thus the overall seroprevalence rate was $29 \%$ [1]. The present study shows that overall seroprevalence was about similar to that reported by Aljumaili, et al. higher than that reported by one study, but lower than that reported by others two studies [1]. Globally, in pregnant women, the seroprevalence of T. gondii IgG was with range of 0.48 in Brazil to $83.5 \%$ in Madagascar $[27,28]$. While in $\mathrm{BOH}$, the global seroprevalence rate range was from $19.44 \%$ to $55.2 \%[2]$.

This and previous studies show global variations in the prevalence rate of $T$. gondii seropositivity among pregnant and non pregnant woman. Toxoplasma infections was associated with education levels, but not reach a significant level, however, others reported significant association with low education level [29]. The present study indicated that $T$. gondii IgG seroprevalence was not significantly varies among the education levels. In addition, the OR not confirms the association between education and T. gondii IgG seroprevalence, but confirmed a significant association for IgM seroprevalence. 


\section{Virology \& Immunology Journal}

Although, $74 \%$ of our study population were educated, still uneducated woman are with more chance to be infected with $T$. gondii. This might be due to personal eating and washing habits. This study results agreed with that reported for Basrah, Tikrit and Sudan, while no one of the other studies performed in Iraq reported any information on such variable [2]. From the present study, it was suggested that sound personal hygiene practice in educated subjects influence and reduce $T$. gondii transmission. This finding confirmed using both Logistic regression and Bivariate analysis, as indicated that higher education was protective against infection.

This study indicated that $T$. gondii seroprevalence was with lower rate in house wife $(22.7 \%)$ as compared to official $(28.9 \%)$, but the difference was not significant. Thus occupation is a risk factor for disease transmission, especially in individuals who was with soil, animal and meat contact. The non predominance of infection in housewives as this study indicated was not in agreement to that reported for Kirkuk, Almothana, Al-Najaf, and Tikrit [2]. However, prevalence rate was about similar to that reported by others in two studies performed in 2013 and 2011, much higher to a third study that reported (3.49 \%) for Kirkuk in 2007 [1,2]. Another three studies performed in Iraq found lower predominance rate of $T$. gondii infection for Baghdad, Basrah and Najaf [2]. One study reported for Basrah, Iraq, did not find relationship between T. gondii infection and occupation [2]. Although the prevalence rate for $T$. gondii infection was lower in house wives but the OR did not confirm the responsibility of such occupation as bivariate and logistic regression analysis demonstrated.

Our findings show that $T$. gondii infections vary remarkably in relation to residence and it was significantly more predominance in urban areas $(26.3 \%)$ as that for rural ( $16.1 \%$ ) areas . Urban women are more prone to $\mathrm{T}$. gondii infections than rural women and this agreed to that reported in Iraq, for Kirkuk, Tikrit, Karbala, and Najaf [2]. However, other studies in Iraq reported that prevalence rate was lower urban areas, such as in Diyala, Tikrit, Kirkuk and AL-Anbar [2]. All the studies reported that high prevalence of $T$. gondii in rural areas present their data as frequency and were not perform any statistical test to determine the association and most of them with small sample size than ours. Globally, human $T$. gondii seroprevalence rates demonstrated variations between countries and different regions with in the same country $[2,30]$. These variations may be a reflection of the differences in food handling and food cooking habits, precaution during farming, animal exposure and personal hygiene.

The presence of IgM antibody in 7 women suggest that $0.84 \%$ active infection may be present in the studied population. Four of them are pregnant and thus IgG avidity confirmatory test or estimation of IgM titers to exclude recent infections are warranted [31]. T. gondii acute infections decline with time from $1.05 \%$ to $0.9 \%$, but IgG seroprevalence was with different pattern [3]. The decline in IgG as a marker of remote infections may take 5 to 10 years to happen in immunocompromised individuals. IgM seroprevalence decline may reflect the disease prevention measures, and the feral cat control or reduction of $T$. gondii cysts in food animals, which mat attribute to reduction in the quantity and quality of oocysts entering the environment. T. gondii association with abortion was with health impact on society to increase the awareness toward prevention of infection. There is one problem that emerged recently which may affect $T$. gondii infection in Iraq is the contamination of meat with the parasite that was imported to Iraq [11]. $T$. gondii prevalence of $23 \%-25 \%$ in sheep was reported in studies performed in region since 2001, which suggest that undercooked lamb meat may be a source of T. gondii infection [32]. In Iraq, there was no feral cat well controlled program and this may attribute to that cats may play an important role in disease spread in the community. T. gondii seroprevalence was significantly higher in non pregnant (3.5\%) women as compared to pregnant women $(18.3 \%)$, which was consistent with other findings for Kirkuk [1,2].

The present study not demonstrated an association between smoking, hemoglobin level, abortion number, congenital anomalies, animal exposure and $T$. gondii seroprevalence. In addition, OR not shows an association, with the exception of abortion number with acute $T$. gondii infection.

In conclusion, age, residence and educational levels may be of positive association with T. gondii in Iraq.

\section{References}

1. Aljumaili ZKM, Alsamarai AGM, Najem WS (2014) Toxoplasma gondii seroprevalence in women with bad obstetric history. MEJIM 74(1): 9-18.

2. Alsamarai AGM, Aljumaili ZK (2013) Seroepidemiology of Toxoplasma, Rubella, Cytomegalovirus and Herpes Simplex Virus -2 in Women with Bad Obstetric History. PART I: 
Toxoplasma and Rubella infections. Our Dermatol 4: 522-535.

3. Aljumaili ZKM, Alsamarai AGM, Najem WS (2013) Seroepidemiological study of toxoplasma, rubella, cytomegalovirus and herpes simplex virus in women with bad obstetric history. MEJIM 6(6): 21-33.

4. Wanachiwanawin D, Sutthent R, Chokephaibulkit K, Mahakittikun V, Ongrotchanakun J, et al. (2001) Toxoplasma gondii antibodies in HIV and non-HIV infected thai pregnant women. Asian Pac J Allergy Immunol 19(4): 291-293.

5. Ribeiro AC, Mutis MS, Fernandes O (2008) Association of the presence of residual antitoxoplasma gondii IgM in pregnant women and their respective family groups in Miracema, northwest Rio de Janeiro, Brazil. Mem Inst Oswaldo Cruz 103(6): 591-594.

6. Buchy P, Follezou JY, Lien TX, An TT, Tram LT, et al. (2003) Serological study of toxoplasmosis in Vietnam in a population of drug users (Ho Chi Minh city) and pregnant women (Nha Trang). Bull Soc Pathol Exot 96(1): 46-47.

7. Liu Q, Wei F, Gao S, Jiang L, Lian H, et al. (2009) Toxoplasma gondii infection in pregnant women in China. Trans R Soc Trop Med Hyg 103(2): 162-166.

8. Ayi I, Edu SA, Apea-Kubi KA, Boamah D, Bosompem KM, et al. (2009) Sero-epidemiology of toxoplasmosis amongst pregnant women in the greater accra region of Ghana. Ghana Med J 43(3): 107-114.

9. Natu M, Joshi BN, Sali N (1989) Toxoplasmosis prevalence in pregnancy with bad obstetric history. Indian J Med Sci 43(1): 291-293.

10. Rai SK, Shibata H, Sumi K, Rai G, Rai N, et al. (1998) Toxoplasma antibody prevalence in Nepalese pregnant women and women with bad obstetric history. Southeast Asian J Trop Med Public Health 29(4): 739-743.

11. Shashi C, Usha A, Aruna A (2005) Prevalence of IgM Anti-bodies to Toxoplasma, Rubella and Cytomegalovirus Infections During Pregnancy. J K Science 6: 190-192.

12. Sadik MS, Fatima H, Jamil K, Patil C (2012) Study of TORCH profile in patients with bad obstetric history. Biology Medicine 4: 95-101.

\section{Virology \& Immunology Journal}

13. Tabbara KS, Saleh F (2005) Serodiagnosis of toxoplasmosis in Bahrain. Saudi Med J 26(9): 13831387.

14. Mossa HAL (2009) Toxoplasmosis in Iraqi women: a retrospective study. Karbala J Med 2: 697-701.

15. El-Deeb HK, Sala-Eldin H, Khodeer S, Allah AA (2012) Prevalence of Toxoplasma gondii in antenatal population in Menoufia governorate, Egypt. Acta Trop 124(3): 185-191.

16. Al-Marzoqi AHM, Kadhim RA, Aljanabi DKF, Hussein HJ, Al Tae ZM (2012) Seroprevalence study of IgG and IgM Antibodies to Toxoplasma, Rubella, Cytomegalovirus, Chlamydia trachomatis and Herpes simplex II in Pregnancy women in Babylon Province. Journal of Biology, Agriculture and Healthcare 2(10): 159-164.

17. Aziz FM, Drueish MJ (2011) Toxoplasmosis: serious disease during pregnancy. Baghdad Sci J 8(1): 91-95.

18. Hadi NJ (2011) Prevalence of Antibodies to Cytomegalovirus, Rubella Virus and Toxoplasma gondii among aborted women in Thiqar province. J Educ Coll 1(5): 3-9.

19. Al-Khashab FMBA, Alhiyali SSM, Dawood IS (2011) Serological diagnosis of acute and chronic infections of Toxoplasma gondii in women with abortion or normal pregnancy. Tik J Pure Sci 16: 52-57.

20. Razzak AH, Wais SA, Saeid AY (2005) Toxoplasmosis: The innocent suspect of pregnancy wastage in Duhok, Iraq. East Mediterr Health J 11(4): 625-632.

21. Hassan HM, Alsamarai AGM, Aljumaili ZK, Alobaidi AHA (2014) Association of Cytomegalovirus Infection and Bad Obstetric Outcome in Women from Kirkuk. Int J Public Health Sci 3(1): 29-42.

22. Frenkel JK, Dubey JP (1972) Toxoplasmosis and its prevention in cats and man. J Infect Dis 126(6): 664673.

23. Abu Madi MA, Al-Molawi N, Behnke JM (2008) Seroprevalence and epidemiological correlations of T. gondii infections among patients referred for hospital based serological testing in Doha, Qatar. Parasit Vectors 1: 39.

24. Petersen E (2007) Toxoplasmosis. Seminar in Fetal \& Neonatal Medicine 12(3): 214-233. 


\section{Virology \& Immunology Journal}

25. Avelino MM, Campos D, Parada JCB, Castro AM (2004) Risk Factors for Toxoplasma gondii Infection in Women of Childbearing Age. Braz J Infect Dis 8(2): 164-174.

26. Jumaian NF (2005) Seroprevalence and risk factors for Toxoplasma infection in pregnant women in Jordan. Eastern Mediterranean Health Journal 11(-1 (2: 45-51.

27. Varella IS, Canti ICT, Santos BR, Coppini AZ, Argondizzo LC, et al. (2009) Prevalence of acute toxoplasmosis infection among 41,112 pregnant women and the mother-to-child transmission rate in a public hospital in south Brazil. Mem Inst Oswaldo Cruz 104(2): 383-388.

28. Lelong B, Rahelimino B, Candolfi E, Ravelojaona BJ, Villard O, et al. (1995) Prevalence of toxoplasmosis in a population of pregnant women in Antananarivo (Madagascar). Bull Soc Pathol Exot 88(1): 46-49.
29. Jones JL, Kruszon-Moran D, Wilson M, McQuillan G, Navin T, et al. (2001) Toxoplasma gondii in the United States: seroprevalence and risk factors. Am J Epidemiol 154(4): 357-365.

30. Tenter AM, Heckeroth AR, Weiss LM (2000) Toxoplasma gondii: from animals to humans. Int J Parasitol 30(12-13): 1217-1258.

31. De Paschale M, Agrappi C, Belvisi L, Cagnin D, Cerulli $\mathrm{T}$, et al. (2008) Revision of the positive predictive value of IgM anti- Toxoplasma antibodies as an index of recent infection. New Microbiol 31(1): 105-111.

32. Acici M, Babuir C, Kilic S, Hokelek M, Kurt M (2008) Prevalence of antibodies to Toxoplasma gondii infection in humans and domestic animals in Samsun province, Turkey. Trop Anim Health Prod 40(5): 311315.

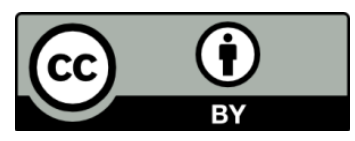

